\title{
Impact of Difficult Airway Training on Performance of Korean Paramedic Students in Simulated Normal and Difficult Airway Scenarios: A Randomized Educational Intervention Study
}

\author{
Chris Richardson \\ Medical student \\ The State University of New York at Stony Brook, U.S.A.
}

\section{Tae-Min Kim}

EMT-P

Associate Professor, Department of Emergency Medical Technician, Cheju Halla University, Korea

\author{
Won Chul Cha \\ MD Instructor \\ Department of Emergency Medicine, Samsung Medical Center, Korea
}

\author{
Edward R. Stapleton \\ EMT-P \\ Associate Professor, Department of Emergency Medicine, \\ The State University of New York at Stony Brook, U.S.A.
}

\begin{abstract}
Aim: Evaluate the impact of difficult airway traning on Korean paramedic students' performance during manikin-based airway management simulations. Methods: 40 Korean paramedic students with previous training in airway management and endotracheal intubation were randomly assigned to an intervention or control group. Students in the intervention group completed 16 additional hours of training using curriculum from the Difficult Airway Course ${ }^{\mathrm{TM}}$. Both groups were then tested on a series of airway management scenarios using a Laerdal SimMan ${ }^{\circledR}$ manikin. Results: All participants were able to secure the airway in a normal intubaion scenario, though the intervention group did so fasster on average (121.9 seconds vs. 161.2 seconds in the control group, $\mathrm{p}=.04$ ). None of the students in the control group were able to secure the airway of a manikin manifesting tongue edema, shile 18 of 20 students in the intervention group sere successful. Students in both groups were equally likily to secure the airway of a manikin fitted with a cervical spine immobilization collar. Students in the intervention group were more likely to employ video laryngoscopy or use a gum elastic bougie to assist during intubaion. On average, students in the intervention group scored significantly higher on a checklist of airway management maneuvers for all three scenarios $(\mathrm{p}<.001)$ and reported higher confidence in their ability to manage both a normal and difficult airway ( $\mathrm{p}=0.011$ and $\mathrm{p}=0.003$, respectively). Conclusion: Difficult airway training improves Korean paramedic students' performance on simulated airway managenent scenarios.
\end{abstract}

Keywords: Paramedic, Simulation, Difficult Airway Course

\section{Introduction}

Airway management is often the first priority in emergency care, yet even in the most developed EMS systems, success rates for paramedics performing endotracheal intubation (ETI) can be highly variable, with overall success rates ranging from 74 percent in non-drug assisted intubations to as high as
96 percent for rapid sequence intubaion. 1,2,3 This variation may be expected, as there in wide variation in the type and frequency of airway procedures performed, environmental factors and the characteristics of patients selected for such procedures.

Common complications that lower ETI success rates include prolonged intubation requiring multiple attempts, inadvertent 
extubations, endotracheal tube cuff ruptures, mainstem bronchus intubation and esophageal intubation. 5 Several factors have been proposed to explain these poor outcomes, including poor initial training, limited reinforcement and frequency of intubations for field providers, lack of physician oversight, and poor monitoring of end tidal carbon dioxide following field intubations.

Various training strategies have been developed to assist anesthesiologists and emergency medical physicians in the management of difficult airways in hospitalized patients. One such strategy is the Difficult Airway Course TM (http:www.theairwaysite. com), a curriculum that has been used extensively to teach anesthesiologists, emergency physicians and pre-hospital providers the skills and strategies for anticipating and managing difficult airways. In this study, we sought to assess the impact of the Difficult Airway Course as an educational intervention for Korean paramedic students who had previously completed a standard airway management curriculum.

Alternative airway devices have been used in prehospital care for decades. This has included the use of the Espohageal Obturator and Gastric Tube Airway, Esophageal Tracheal Combitube, King LT airway, and several other devices. Multiple studies have demonstrated their relative effectiveness when compared to Bag Mask and ETI ventilation. However, many training programs deemphasize the use of these devices that may serve as important rescue strategies, when intubation fails.

The use of a training program that incorporates evaluation of the airway, a systematic to airway management, and exposure to a wide variety of rescue devices may prove vaulable to the prehospital provider.

\section{Methods}

\subsection{Participants}

After appropriate ethics committee approval, 40 thirdyear paramedic students at Cheju Halla University in Jeju, Korea were recruited for participation in an educational intervention study and randomised into either a control or intervention group. Basic demographic characteristics of each group are shown in Table 1.

Table 1: Demographic characteristics of the control and intervention groups were not significantly different in age $(p=.65)$ or gender composition $(p=68)$.

\begin{tabular}{ccc}
\hline & Intervention & Control \\
\hline Median Age & 24 years & 23.5 years \\
\hline Males & 17 & 16 \\
\hline Females & 3 & 4 \\
\hline
\end{tabular}

\subsection{Prior Training}

Students in both groups completed approximately 60 hours of airway management training together as part of their Paramedic curriculum. This training included 16 hours of lecture and 24 hours of hands-on instruction using manikin simulations and scenario practice. This curriculum included exposure to assessment of the airway and breathing, bag-valve mask ventilation, placement of supraglottic devices such as the laryngeal mask airway (LMA) and King ${ }^{\circledR}$ LT airway, and insertion of an endotracheal tube using direct laryngoscopy.

\subsection{Difficult Airway Training}

The twenty students in the intervention group received 16 hours of additional instruction as presented in the Difficult Airway Course ${ }^{\mathrm{TM}}$ (http://www.theairwaysite.com) by a staff member at the Cheju Halla University who had been trained in this curriculum. This training included lectures focused on predicting the difficult airway and using a structured problemsolving approach for assessing and securing the airway in a variety of scenarios. As part of the course, students also received instruction in using video laryngoscopy, flexible fiberoptic laryngoscopy, and using a bougie or intubating LMA to assist placement of an endotracheal tube in the setting of a difficult airway. All lectures, simulations and reading materials were provided to the students in the Korean language.

\subsection{Assessment Procedure}

One week after the conclusion of training for the intervention 
group, both groups of students convened for the assess-ment phase of the study. Each participant rotated through a series of three simulated airway management scenarios using a Laerdal SimMan ${ }^{\circledR}$ manikin: (i) normal airway; (ii) simulated tongue edema; (iii) simulated trauma patient fitted with a cervical collar and decreased cervical range of motion. Students were told in advance that they would be expected to demonstrate their airway management skills, but were not informed of the details of the scenarios until they arrived in the examination room.

Before beginning the simulation, each student was oriented to the equipment available, which was tested in advance to confirm that it would work properly with the manikin. Each student was supplied the following: oral pharyngeal airway, nasal pharyngeal airway, lubricant spray, bagvalve mask, laryngoscope, MacIntosh blade, Miller blade, 7.0mmendotracheal tube, stylet, $10 \mathrm{~mL}$ syringe, GlideScope ${ }^{\circledR}$ Cobalt video laryngoscope with stylet, Pentax ${ }^{\circledR}$ Airway Scope video laryngoscope with stylet, LMA, intubating LMA, King ${ }^{\circledR}$ LT supraglottic airway, Combitube ${ }^{\circledR}$ Airway. Students also had access to a stethoscope and end-tidal CO2 detector to confirm proper placement of the endotracheal tube or supraglottic device and an endotracheal tube holder to secure the tube.

In each case, participants were instructed to assess and secure the airway (provide positive-pressure ventilation and protection against aspiration) using any manoeuvers or equipment they felt necessary. An assistant was available to deliver bagvalvemask ventilation or hold equipment, as directed by the study participant. This assistant provided no other guidance or assistance.

\subsection{Data Collection and Analysis}

The primary end-point for this study was the time required for each student to assess the simulated patient and secure the airway with an appropriate device. During each simulation, a video camera was focused on the head and torso of the manikin to record the encounter. A research assistant reviewed each video and used a stopwatch to measure the time it took to achieve the first breath with a definitive device (defined as bilateral chest rise following insertion of an endotracheal tube or supraglottic device), the time to perform the actual intubation or supraglottic airway insertion procedure, and the total time spent on scene performing airway management maneuvers (including any time spent confirming and securing proper endotracheal tube placement).

The research assistant also recorded the number of attempts each participant made to secure the airway and the device or devices used. An attempt was defined as the insertion of a laryngoscope or supraglottic device into the oropharynx, combined with a motion intended to allow visualization of the glottic opening (during laryngoscopy) or secure placement of the supraglottic device.

An examiner was present in the examination room to introduce each scenario to the examinee. These examiners were provided with a checklist of skills and manoeuvers the examinees should demonstrate during their attempt to secure the airway and recorded whether or not these were properly performed. The skills assessed for each scenario are shown in Table 3. The examiners were faculty who had assisted with instruction for the intervention group, so they were not blinded to the participants' status as part of the control or intervention groups.

Finally, before completing the simulation scenarios, participants also completed a short attitudes survey regarding their perceived preparedness to manage a patient with a normal or difficult airway.

To compare the mean time on scene until first airway secured and mean length of successful intubation attempt we used the Mann-Whitney U test and to compare the survival distributions for these end-points we used the log-rank test. To compare the percentage of successful intubations on first attempt we used the chi-squared test. To compare the number of airway maneuver attempts we used generalized linear models for Poisson counts. To compare the percentage of airway manoeuvers completed we used the Mann-Whitney U test. To compare the distribution of devices used in each simulation and the responses to the attitudes survey we used the chisquared test. 


\section{Results}

All 40 participants enrolled in the study participated fully in the training (if assigned to the intervention group) and assessment phases.

\subsection{Primary Outcomes:}

As shown in Figure 1, participants in the intervention group were able to assess the simulated patient, insert an appropriate airway and deliver effective ventilation faster than students in the control group for the normal intubation $(a, p=X X X)$ and tongue edema $(b, p<0.001)$ scenarios. There was no difference in the cervical spine immobilization scenario ( $c, p=0.53$ ).

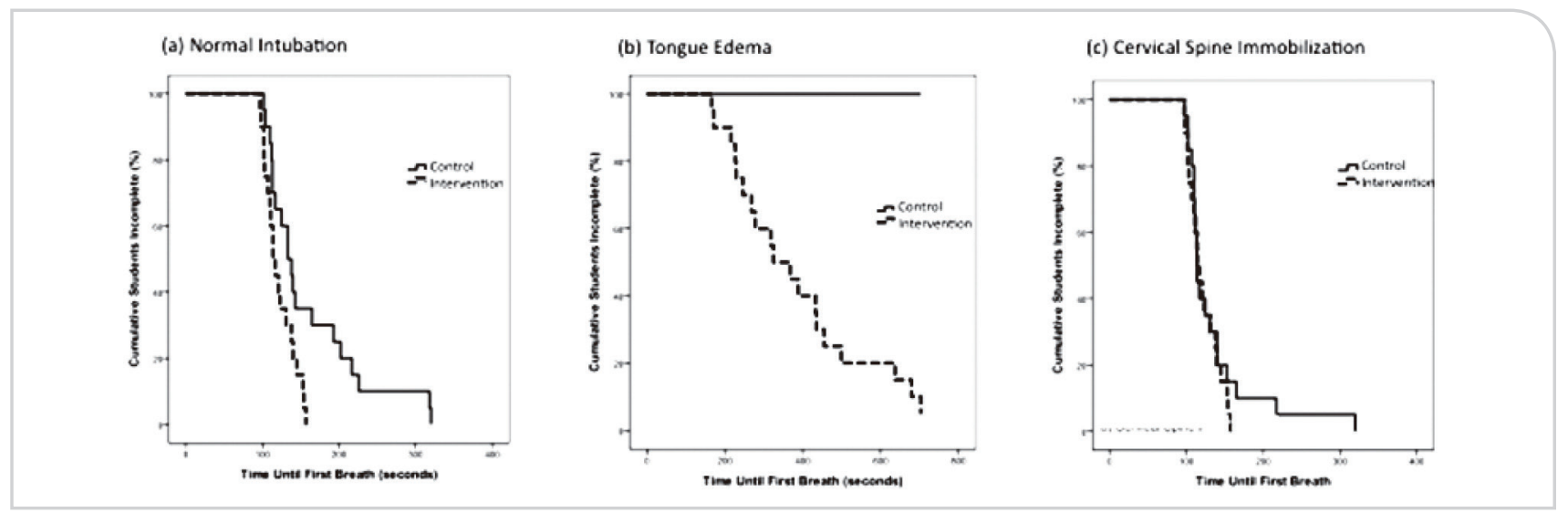

Figure 1. Survival Analysis.

Figure 1. Time until first breath in (a) normal, (b) tongue edema and (c) cervical spine immobilized groups.

Table 2: Timing and attempts in (a) normal, (b) tongue edema and (c) cervical spine immobilized groups.

\begin{tabular}{|c|c|c|c|c|c|c|c|c|c|}
\hline & \multicolumn{3}{|c|}{ Normal Intubation } & \multicolumn{3}{|c|}{ Tongue Edema } & \multicolumn{3}{|c|}{ Cervical Spine Immobillization } \\
\hline & Intervertion & Control & p-value & Intervertion & Control & p-value & Intervertion & Control & p-value \\
\hline $\begin{array}{l}\text { Mean Length of } \\
\text { Successful Intubation } \\
\text { Attempt }\end{array}$ & $40.9 \mathrm{~s}$ & $57.35 \mathrm{~s}$ & 0.16 & $48.8 \mathrm{~s}$ & $\mathrm{n}=0$ & $<0.001$ & $51.55 \mathrm{~s}$ & $49.4 \mathrm{~s}$ & 0.40 \\
\hline $\begin{array}{l}\text { Mean Time On Scene } \\
\text { Until Airway Secured }\end{array}$ & $121.85 \mathrm{~s}$ & $161.2 \mathrm{~s}$ & 0.040 & $371 \mathrm{~s}$ & $\mathrm{n}=0$ & $<0.001$ & $132.85 \mathrm{~s}$ & $146.1 \mathrm{~s}$ & 0.53 \\
\hline $\begin{array}{l}\text { Secured Airway on } \\
\text { First Attempt }\end{array}$ & $\begin{array}{l}18 / 20 \\
(90 \%)\end{array}$ & $\begin{array}{l}16 / 20 \\
(80 \%)\end{array}$ & 0.15 & $\begin{array}{l}0 / 20 \\
(0 \%)\end{array}$ & $\begin{array}{l}0 / 20 \\
(0 \%)\end{array}$ & 1.00 & $\begin{array}{l}17 / 20 \\
(85 \%)\end{array}$ & $\begin{array}{l}12 / 20 \\
(60 \%)\end{array}$ & 0.08 \\
\hline $\begin{array}{l}\text { Mean \# Airway } \\
\text { Maneuver Attempts }\end{array}$ & 1.1 & 1.3 & 0.66 & 3.85 & 2.7 & 0.046 & 1.15 & 1.6 & 0.23 \\
\hline $\begin{array}{l}\text { Mean \# of Different } \\
\text { Devices Used in } \\
\text { Attempts to Secure } \\
\text { Airway }\end{array}$ & 1.0 & 1.0 & $X X$ & 3.15 & 2.65 & $X X$ & 1 & 1.1 & $x X$ \\
\hline $\begin{array}{l}\text { \# of Students } \\
\text { Ultimately Achieving } \\
\text { Definitive Airway } \\
\text { Management }\end{array}$ & $\begin{array}{l}20 / 20 \\
(100 \%)\end{array}$ & $\begin{array}{c}20 / 20 \\
(100 \%)\end{array}$ & $X X$ & $\begin{array}{l}18 / 20 \\
(90 \%)\end{array}$ & $\begin{array}{l}0 / 20 \\
(0 \%)\end{array}$ & $X X$ & $\begin{array}{c}20 / 20 \\
(100 \%)\end{array}$ & $\begin{array}{l}19 / 20 \\
(95 \%)\end{array}$ & $X X$ \\
\hline
\end{tabular}


In the normal intubation scenario, all participants in both groups were able to secure the airway. The time to perform the intubation procedure itself was not significantly different. The percentage of students in each group securing the airway on the first attempt was not significantly different (Table 2).

In the tongue edema scenario, none of the students in the control group were able to secure the airway, while 18 of 20 students in the intervention group eventually did so. On average, they used 3.15 different devices and 3.85 separate attempts to secure the airway, requiring 371 seconds before the first breath was delivered through a definitive device (Table 2).

In the cervical spine immobilization scenario, 19 of 20 students in the control group and all 20 students in the intervention group were able to intubate the manikin. The time for delivering the first breath through the endotracheal tube and the time for the intubation procedure itself were not significantly different between groups. The percentage of students in each group securing the airway on the first attempt was not significantly different (Table 2).

\subsection{Devices Used By the Two Groups}

In the normal intubation scenario, students in both groups generally used direct laryngoscopy. Although two students in the intervention group used a bougie to assist intubation, there was no significant difference overall in the types of devices used by participants in each group (Figure 2a).

In the tongue edema scenario, students in the control group tended to use direct laryngoscopy or a supraglottic device such as a Combitube ${ }^{\circledR}$ Airway or LMA, but were unable to achieve effective ventilation. Students in the intervention group frequently attempted the use of a supraglottic device initially,

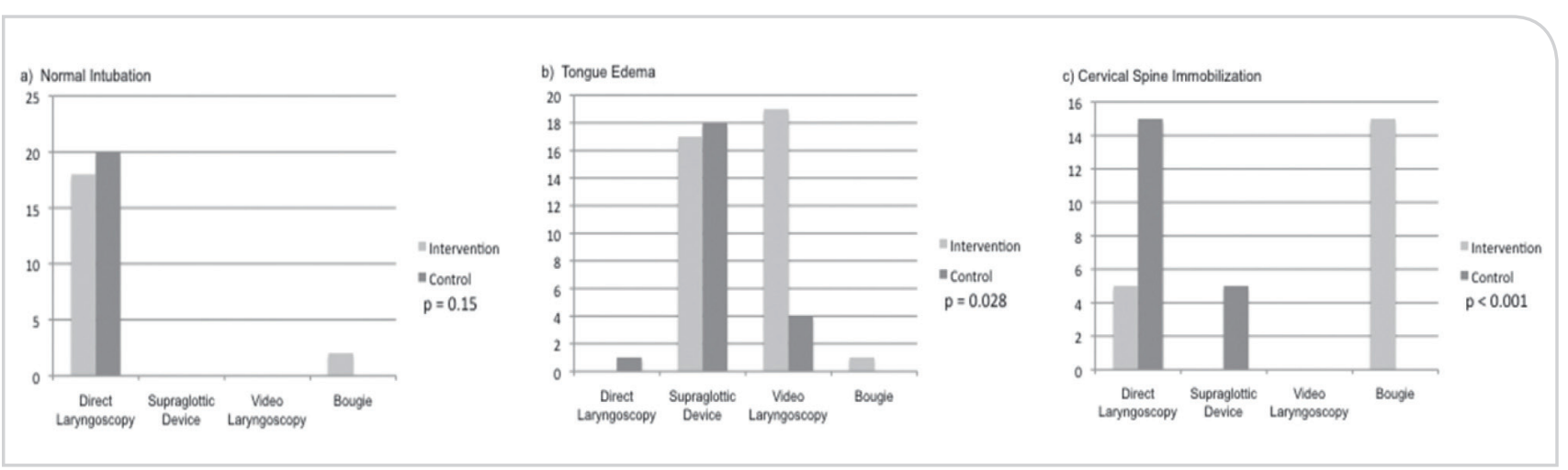

Figure 2. Different Devices Used In Each Scenario. Some students used more than one type of device in a given simulation scenario.

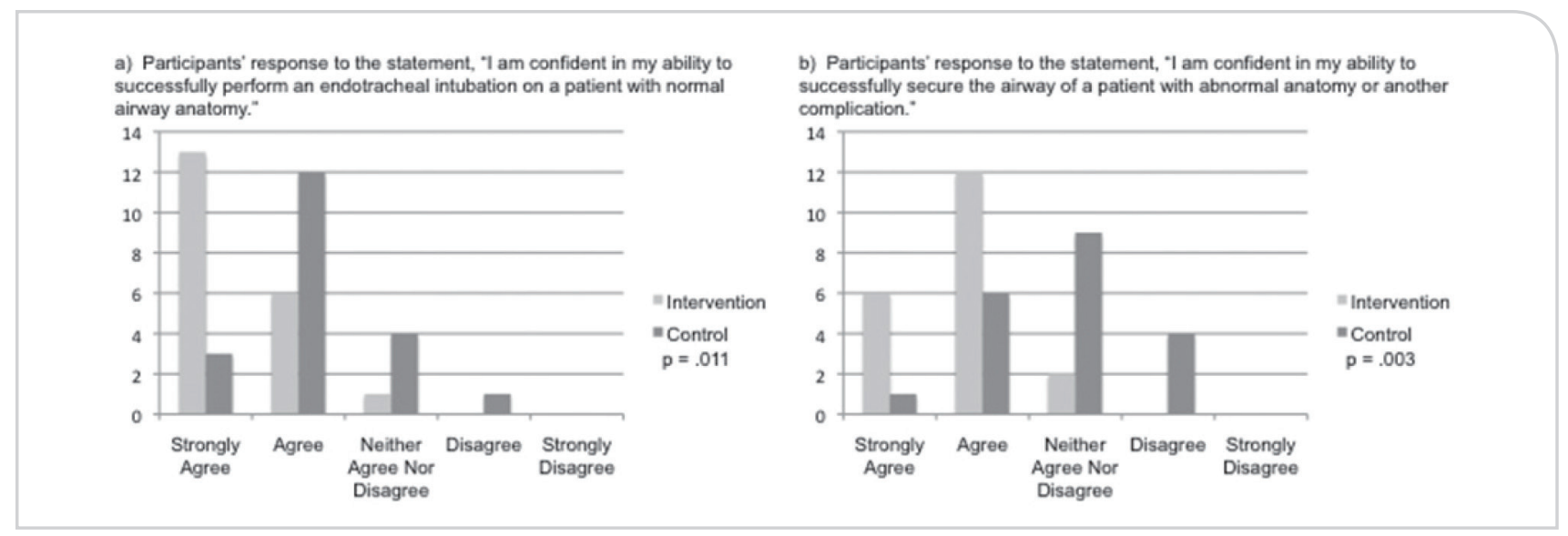

Figure 3. Survey Results 
Table 3: Individual Airway Management Skills Assessment

\begin{tabular}{|c|c|c|c|c|c|c|}
\hline & \multicolumn{2}{|c|}{ Standard Intubation } & \multicolumn{2}{|c|}{ Tongue Edema } & \multicolumn{2}{|c|}{$\begin{array}{l}\text { Cervical Spine } \\
\text { Immobilization }\end{array}$} \\
\hline & intervention & Control & intervention & Control & intervention & Control \\
\hline $\begin{array}{l}\text { Opens airway manually and checks for breathing } \\
\text { (not breathing) }\end{array}$ & 19 & 6 & 19 & 0 & 17 & 5 \\
\hline $\begin{array}{l}\text { Properly inserts nasopharyngeal or oropharyngeal } \\
\text { airway }\end{array}$ & 20 & 17 & 20 & 20 & 19 & 18 \\
\hline $\begin{array}{l}\text { Attempts to ventilate the patient immediately using a } \\
\text { BVM }\end{array}$ & 20 & 20 & 20 & 20 & 20 & 20 \\
\hline Achieves consistent chest rise & 19 & 20 & & & 20 & 16 \\
\hline Selects proper equipment for endotracheal ntubation & 20 & 20 & 20 & 18 & 20 & 18 \\
\hline Positions the manikin's head properly & 10 & 7 & 17 & 18 & 16 & 16 \\
\hline $\begin{array}{l}\text { Inserts the laryngoscope blade into the right side of } \\
\text { the patient's mouth }\end{array}$ & 1 & 0 & 8 & 5 & 1 & 1 \\
\hline Does not use teeth as a fulcrum & 19 & 18 & 19 & 17 & 17 & 16 \\
\hline Advances the tube to the proper depth & 20 & 16 & & & 19 & 17 \\
\hline Inflates the cuff with appropriate volume/pressure & 18 & 20 & & & 19 & 18 \\
\hline $\begin{array}{l}\text { Confirms proper placement of endotracheal tube by } \\
\text { auscultation of lungs }\end{array}$ & 19 & 17 & 18 & 0 & 18 & 15 \\
\hline $\begin{array}{l}\text { Confirms proper placement of endotracheal tube by } \\
\text { auscultation of epigastrium }\end{array}$ & 19 & 17 & & & 18 & 14 \\
\hline $\begin{array}{l}\text { Confirms proper placement of endotracheal tube by } \\
\text { End Tidal CO2 monitoring }\end{array}$ & 15 & 10 & 16 & 0 & 17 & 11 \\
\hline Properly secures device & 20 & 18 & 18 & 0 & 17 & 15 \\
\hline Ventilates at the appropriate rate & 20 & 20 & 19 & 1 & 20 & 19 \\
\hline Recognizes ineffective BVM ventilation & & & 4 & 2 & & \\
\hline Selects alternative strategy if direct laryngoscopy fails & & & 20 & 18 & & \\
\hline Employs correct technique for strategy & & & 16 & 12 & & \\
\hline Achieves adequate ventilation & & & 18 & 0 & & \\
\hline Maintains in-line immobilization & & & & & 14 & 9 \\
\hline \multirow[t]{2}{*}{ MEAN TOTAL SCORE ON SKILLS TEST } & $86.3 \%$ & $75.3 \%$ & $84.0 \%$ & $44.3 \%$ & $85.0 \%$ & $71.3 \%$ \\
\hline & \multicolumn{2}{|c|}{$p<.001$} & \multicolumn{2}{|c|}{$p<.001$} & \multicolumn{2}{|c|}{$p<.001$} \\
\hline
\end{tabular}


but were much more likely to use video laryngoscopy on further attempts. Overall, there was a significant difference in the types of devices used by participants in each group (Figure $2 b$ ).

In the cervical spine immobilization scenario, students in the control group tended to use either direct laryngoscopy or a supraglottic device, while students in the intervention group frequently chose to use a bougie to assist intubation. Overall, there was a significant difference in the types of devices used by participants in each group (Figure 2c).

\subsection{Airway Management Skills Demonstrated}

While completing each simulation, participants were scored on a series of skills and maneuvers. Table 3 shows the skills assessed for each simulation scenario and the number of students within each group completing each step. In each scenario, students in the intervention group completed significantly more total steps on average than students in the control group ( $\mathrm{p}<0.001$ for all scenarios).

\subsection{Attitudes Survey}

As shown in Figure 3, students in the intervention group were more likely to strongly agree with the statement, "I am confident in my ability to successfully perform an endotracheal intubation on a patient with normal airway anatomy," and strongly agree or agree with the statement, "I am confident in my ability to successfully secure the airway of a patient with abnormal anatomy or another complication."

\section{Implications}

There are limitations to this study. First, it is a manikin study and may not adequately represent these conditions in the field. Secondly, the results from this study require a careful interpretation due to the small sample sizes used. It is also important to note that use of advanced airway devices by paramedics in Korea is limited due to government regulations and physician-led current practice. Nevertheless, this study has made an important step to improve training of paramedics in Korea. In this study, exposure to diverse strategies for airway management significantly improved performance in a simulated scenario. Strengthening paramedic performance through the use of innovative training strategies is likely to advance EMS field care and performance by providers. Empirical studies are needed to measure the true impact of Difficult Airway Training on the patient care provided by EMS providers. Another implication is that the results have provided academics with an opportunity to critically discuss if and how these strategies can be implemented in curriculum. The discussion on educational benefits and challenges in making extra training available to all students will be an essential step to start with.

\section{Conclusions}

Difficult airway training improves Korean paramedic students' performance on simulated airway management scenarios. Further field clinical studies are needed to determine the true benefit of this and other training strategies on the performance of airway management by paramedics.

\section{References}

Wang HE, Mann NC, Mears G, Jacobson K, Yealy DM. Outof-hospital airway management in the United States. Resuscitation. 2011 Apr;82(4):378-85.

Lossius HM, Røislien J, Lockey DJ. Patient safety in prehospital emergency tracheal intubation: a comprehensive meta-analysis of the intubation success rates of EMS providers. Crit Care. 2012 Feb 11;16(1):R24.

Frascone RJ, Russi C, Lick C, Conterato M, Wewerka SS, Griffith KR, Myers L, Conners J, Salzman JG. Comparison of prehospital insertion success rates and time to insertion between standard endotracheal intubation and a supraglottic airway. Resuscitation. 2011 Dec;82(12):152936.

Merlin MA, Safdar H, Calabrese S, Lewinsky A, Manfre J, Van Pelt S, Marques-Baptista A. Prehospital rapid sequence intubation in an emergency medical services system with two advanced life support providers. Prehosp Disaster Med. 2010 Jul-Aug;25(4):341-5.

Hubble MW, Wilfong DA, Brown LH, Hertelendy A, Benner RW. A meta-analysis of prehospital airway control techniques part II: alternative airway devices and 
cricothyrotomy success rates. Prehosp Emerg Care. 2010 Oct-Dec;14(4):515-30.

Thomas S, Judge T, Lowell MJ, MacDonald RD, Madden J, Pickett K, Werman HA, Shear ML, Patel P, Starr G, Chesney M, Domeier R, Frantz P, Funk D, Greenberg RD. Airway management success and hypoxemia rates in air and ground critical care transport: a prospective multicenter study. Prehosp Emerg Care. 2010 JulSep;14(3):283.

Cushman JT, Zachary Hettinger A, Farney A, Shah MN. Effect of intensive physician oversight on a prehospital rapid-sequence intubation program. Prehosp Emerg Care. 2010 Jul-Sep;14(3):310-6.

Reich AJ. Good intubators do it more often. The frequency of training, more than total hours spent, seems to correlate with higher ETI success rates. EMS Mag. 2009 Sep;38(9):58-60.

Cady CE, Pirrallo RG. The effect of Combitube use on paramedic experience in endotracheal intubation. Am J Emerg Med. 2005 Nov;23(7):868-71.

Colwell CB, McVaney KE, Haukoos JS, Wiebe DP, Gravitz CS, Dunn WW, Bryan T. An evaluation of out-of-hospital advanced airway management in an urban setting. Acad Emerg Med. 2005 May;12(5):417-22.

Garza AG, Gratton MC, Coontz D, Noble E, Ma OJ. Effect of paramedic experience on orotracheal intubation success rates. J Emerg Med. 2003 Oct;25(3):251-6.

Jemmett ME, Kendal KM, Fourre MW, Burton JH. Unrecognized misplacement of endotracheal tubes in a mixed urban to rural emergency medical services setting. Acad Emerg Med. 2003 Sep;10(9):961-5.

Wang HE, Kupas DF, Paris PM, Bates RR, Yealy DM. Preliminary experience with a prospective, multicentered evaluation of out-of-hospital endotracheal intubation. Resuscitation. 2003 Jul;58(1):49-58.

Pinchalk M, Roth RN, Paris PM, Hostler D. Comparison of times to intubate a simulated trauma patient in two positions. Prehosp Emerg Care. 2003 Apr-Jun;7(2):252-7.

Kaye K, Frascone RJ, Held T. Prehospital rapid-sequence intubation: a pilot training program. Prehosp Emerg Care. 2003 Apr-Jun;7(2):235-40.
Bradley JS, Billows GL, Olinger ML, Boha SP, Cordell WH, Nelson DR. Prehospital oral endotracheal intubation by rural basic emergency medical technicians. Ann Emerg Med. 1998 Jul;32(1):26-32.

Larmon B, Schriger DL, Snelling R, Morgan MT. Results of a 4-hour endotracheal intubation class for EMT-basics. Ann Emerg Med. 1998 Feb;31(2):224-7.

Harrison T, Thomas SH, Wedel SK. In-flight oral endotracheal intubation. Am J Emerg Med. 1997 Oct;15(6):558-61.

Krisanda TJ, Eitel DR, Hess D, Ormanoski R, Bernini R, Sabulsky N. An analysis of invasive airway management in a suburban emergency medical services system. Prehosp Disaster Med. 1992 Apr-Jun;7(2):121-6. 